
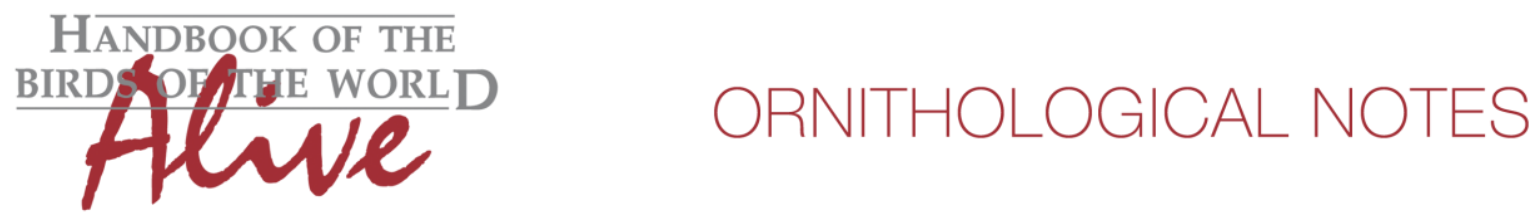

\title{
Notes on the vocalizations of Grey-backed Camaroptera (Camaroptera brachyura)
}

\author{
Peter Boesman
}

In the following we briefly analyze and compare voice of the different races of Grey-backed Camaroptera (Camaroptera brachyura). We also try to quantify the extent of any vocal differences using the criteria proposed by Tobias et al. (2010), as a support for taxonomic review. We have made use of sound recordings available on-line from Xeno Canto (XC).

Our main interest is to compare the two groups which are treated as two species in some taxonomies, primarily based on morphological features: Grey-backed and Green-backed Camaroptera.

Song of both groups is a series of repeated identical notes (or phrases consisting of a few notes). Note shapes are variable, but always include steeply-sloped upslurred or downslurred notes or elements. Some song phrases of Green-backed and Grey-backed Camaroptera are about identical. On average, there seem to be subtle differences between the most frequently used phrases.

Typical examples of Grey-backed Camaroptera (notes or elements clearly 'split' at lowest pitch):

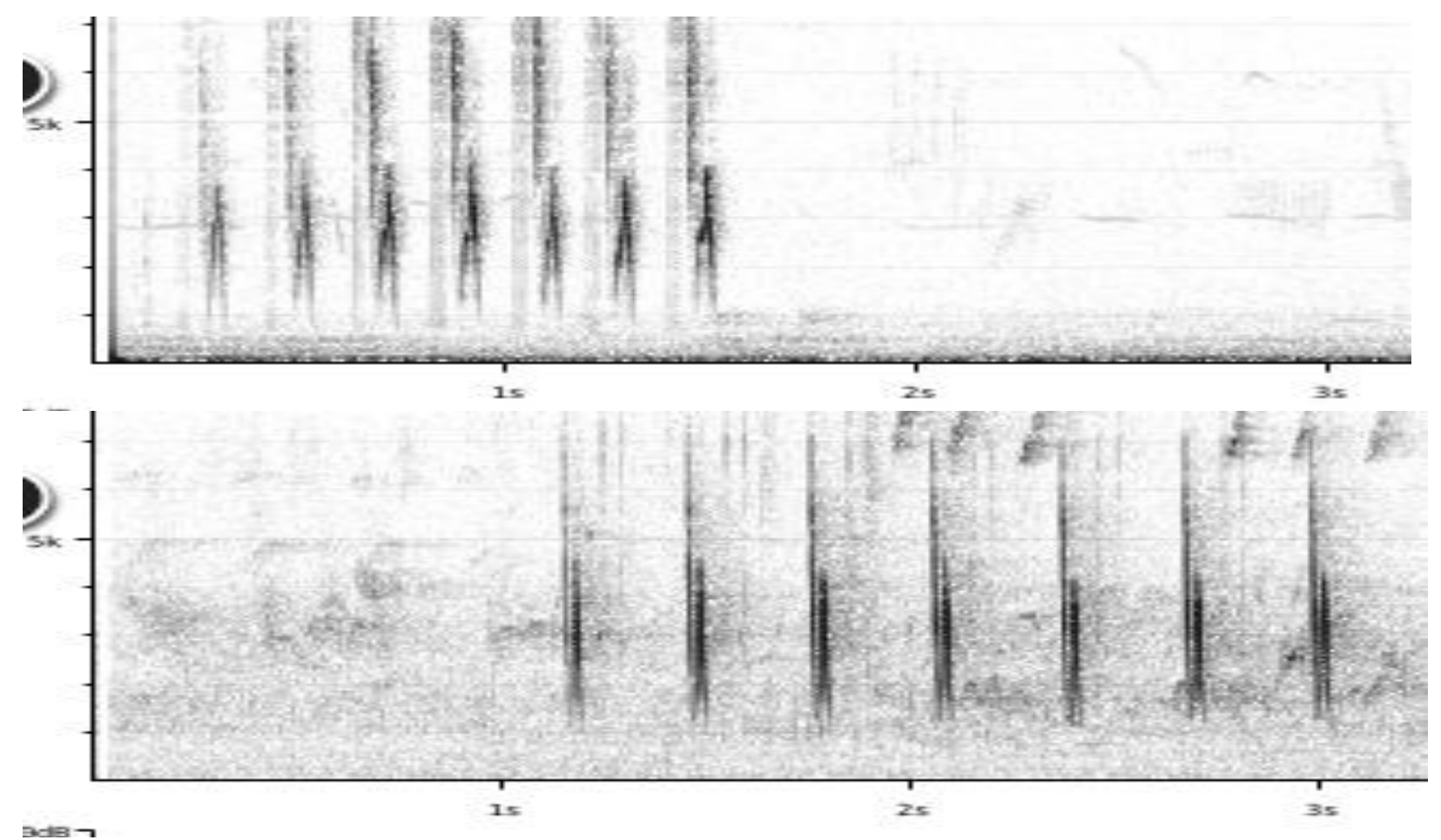


HANDBOOK OF THE

BIRD PF/THE WORLD

ORNITHOLOGICAL NOTES
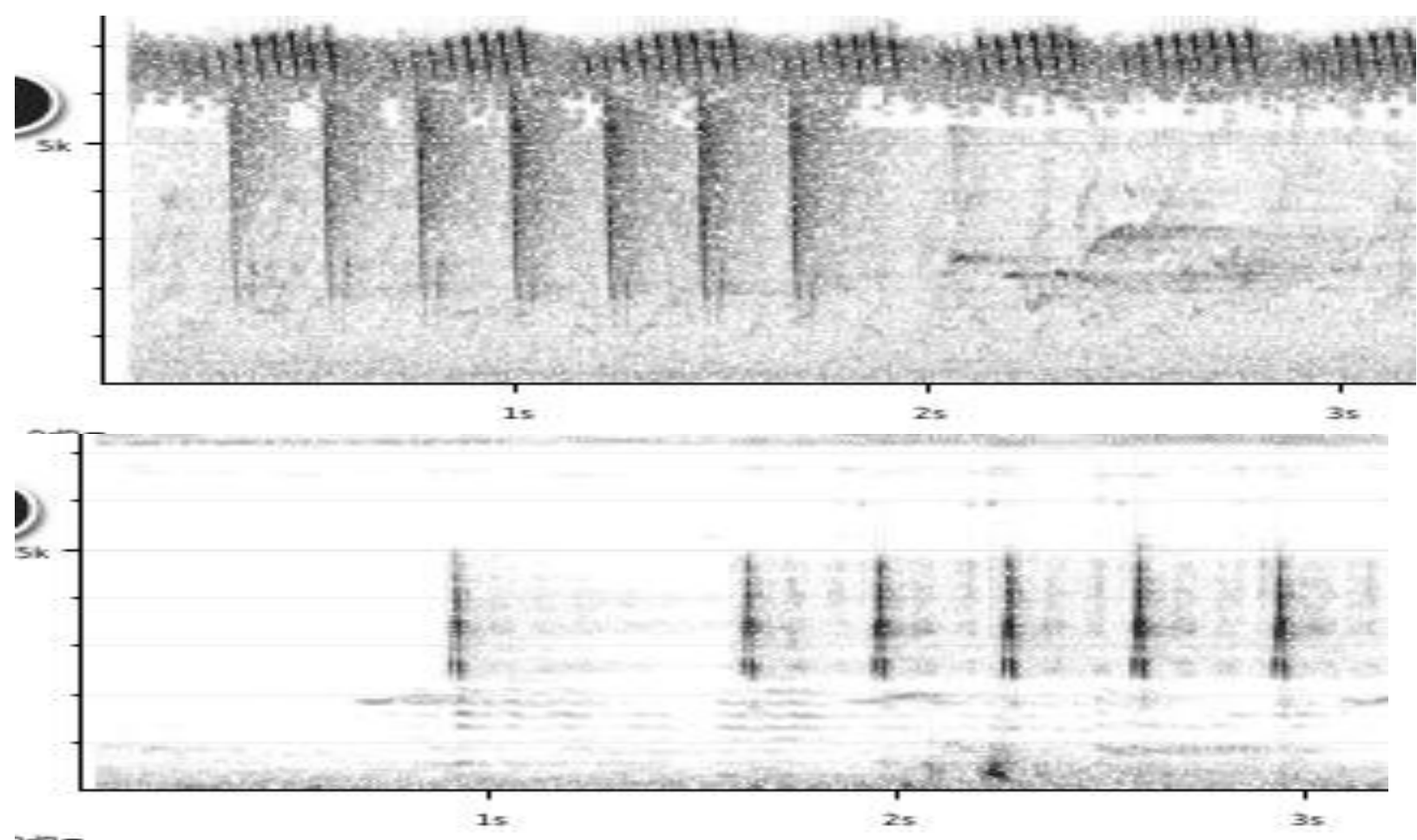

Typical examples of Green-backed Camaroptera: V-shaped notes
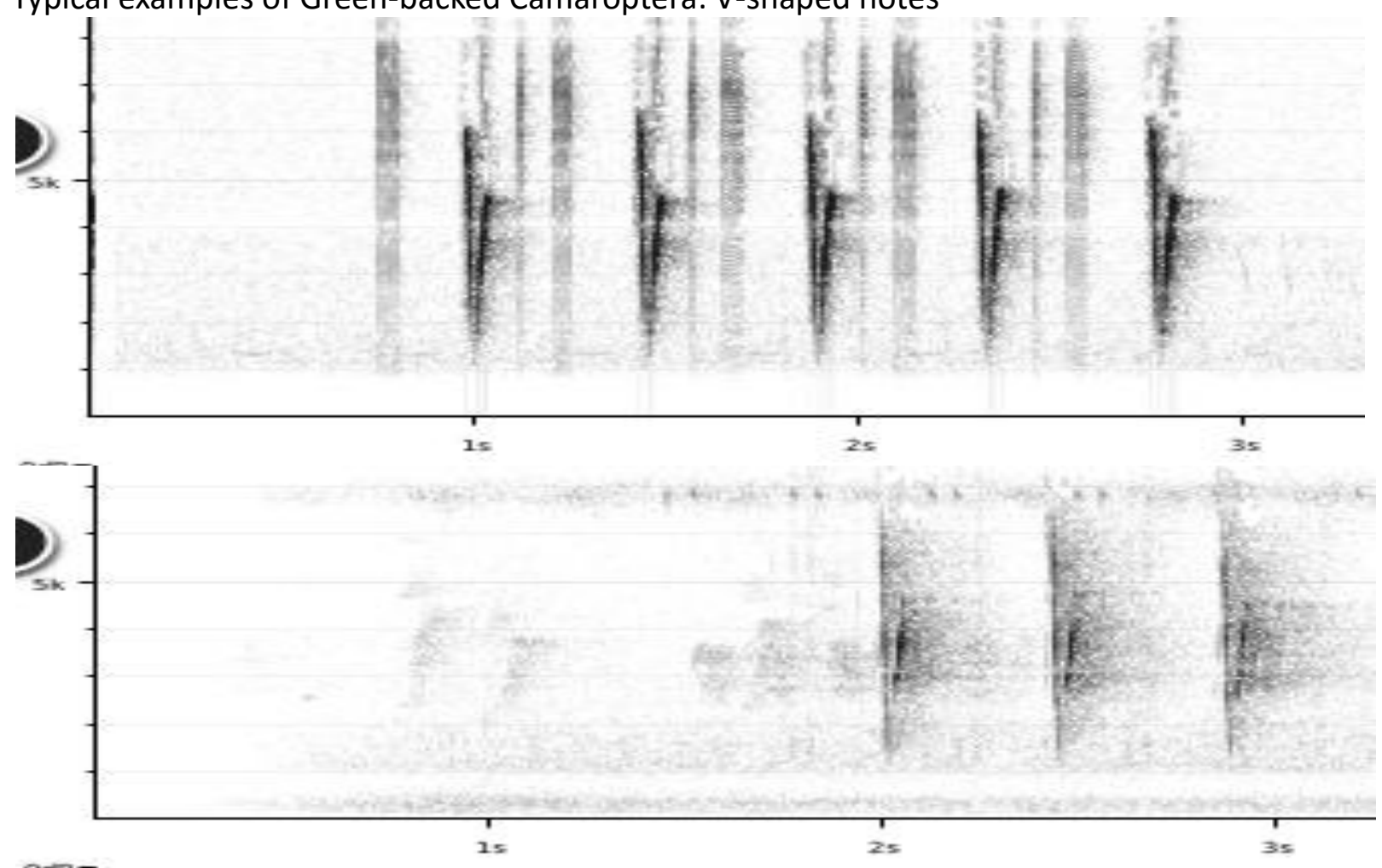

2 

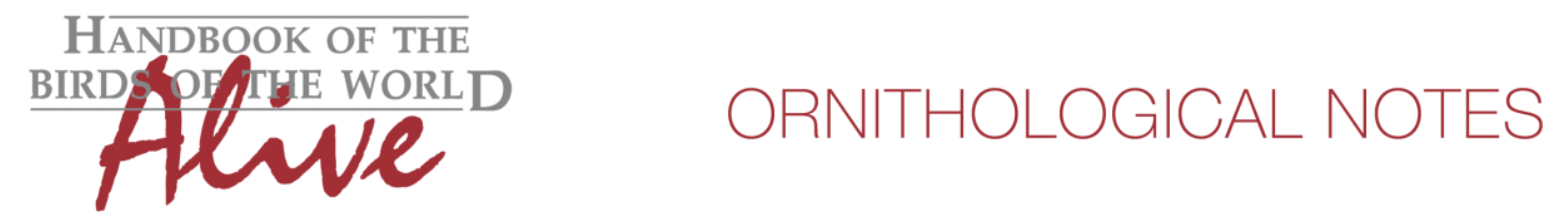

But: Similar examples of Grey-backed Camaroptera do exist (XC280281, XC213630 from southern part of range in contact zone, but also e.g. XC58641 from C Namibia well away from contact zone):
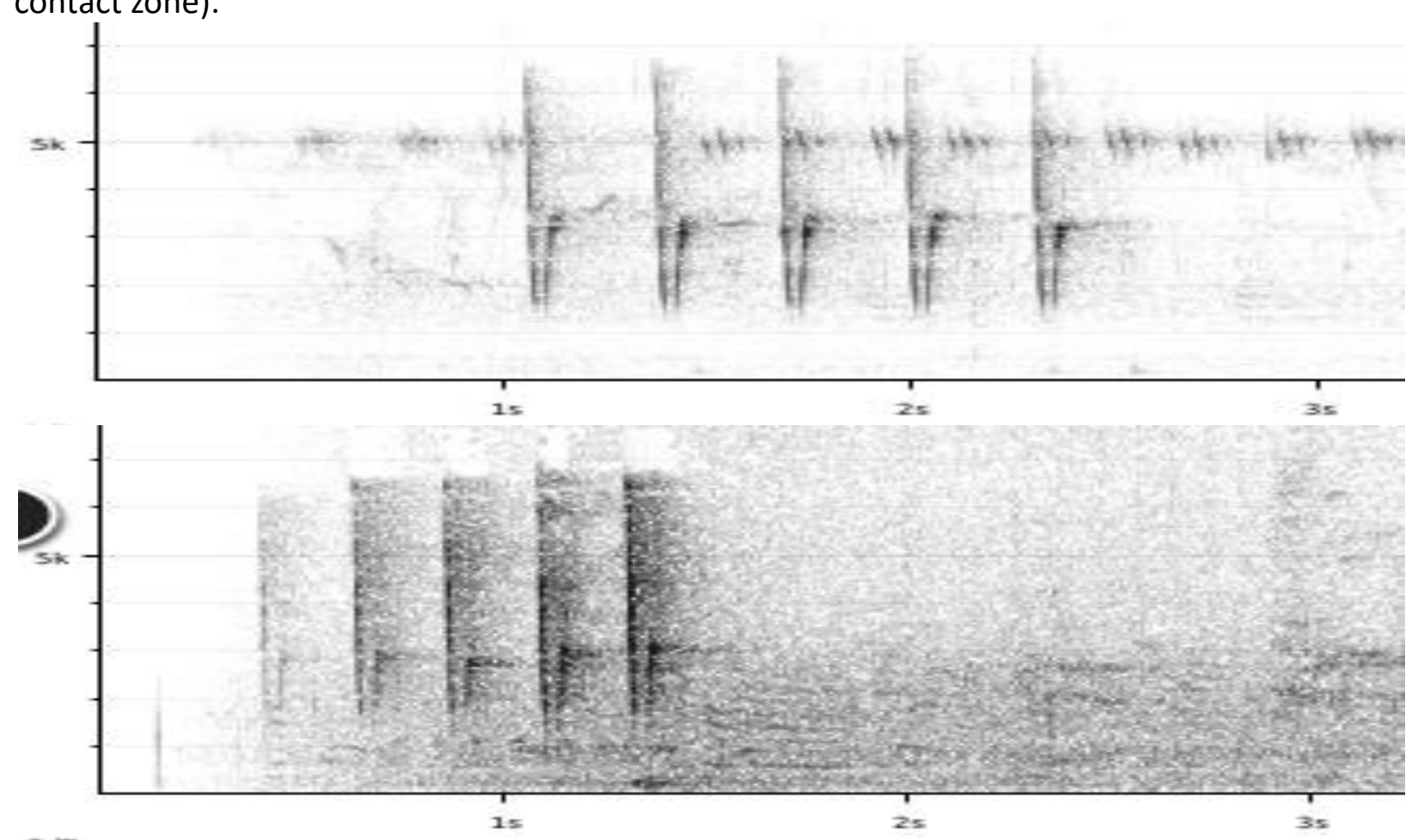

And in the same way, a small number of recordings of Green-backed Camaroptera are of the 'split' type.

It would require more time to analyse all recordings and process statistically to reach a quantification of vocal differences. It is quite clear however that there are two fairly distinct song types, that these are used by both groups but in a very different proportion. The few available recordings from Zambia and Namibia seem to indicate that these populations sing typically the 'V-type song' (as Green-backed Camaroptera), and the vocal difference thus does not necessarily coincide with the two above mentioned groups. The vocal break may actually occur somewhere in SC Africa, where there are at present very few recordings. This will have to be investigated further, when more recordings become available.

This note was finalized on 10th February 2016, using sound recordings available on-line at that moment. We would like to thank in particular the many sound recordists who placed their recordings for this species on XC.

\section{References}

Tobias, J.A., Seddon, N., Spottiswoode, C.N., Pilgrim, J.D., Fishpool, L.D.C. \& Collar, N.J. (2010). Quantitative criteria for species delimitation. Ibis 152(4): 724-746. 


\section{Recommended citation}

Boesman, P. (2016). Notes on the vocalizations of Grey-backed Camaroptera (Camaroptera brachyura). HBW Alive Ornithological Note 223. In: Handbook of the Birds of the World Alive. Lynx Edicions, Barcelona. (retrieved from http://www.hbw.com/node/932182 on 7 September 2016). 